\title{
Os deveres de obediência e sigilo do funcionário público
}

\author{
Fernando Henrique Mendes de Almeida \\ Livre docente de Direito Administrativo na \\ Universidade de São Paulo.
}

\section{I \\ Razões de ordem}

1 - O presente trabalhinho contém um esbôço de teoria jurídica a propósito dos deveres inscritos no título que o seu texto pretende desempenhar. Por esta razão, dividimo-lo em duas partes consagradas respectivamente: a) ao dever de obediência do funcionário público; b) ao dever de sigilo do funcionário público.

\section{II}

Dever de obediência

1) Introdução.

2 - Entre os deveres mencionados em todos os estatutos nacionais de funcionários públicos no Brasil, figura o de êles obedecerem as ordens de seus superiores hierárquicos. Por superiores hierárquicos entender-se-ão: a) o funcionário imediatamente superior ao que deve obedecer; b) qualquer funcionário que, embora mediata, ou remotamente superior ao que deve obedecer tenha competência para emanar as ordens que, em cada caso concreto, sejam dadas. 
2-A - Não basta que-um superior hierárquico leia em texto estatutário menção ao dever de que tratamos, a fim de que se ponha a emanar ordens, de variado conteúdo, no pressuposto de que, por provirem de um chefe, devem ser cumpridas. O assunto é melindroso. Para resolvê-lo, não é suficiente a persuasão de que somos detentores do senso-comum, como ocorre freqüentemente na prática. Pelo contrário. Elle exige auto-crítica em quem ordena, o que infelizmente é o que tanto nos falta, amiúde.

2) Premissas.

3 - Urge, antes de tudo, lembrar aqui: o dever de obediência envolve uma relação jurídica, acessória, de outra, isto é, a da função pública. Manifesta-se: a) em potência; b) em ato. Em potência, aparece, quando, nomeado, investido, compromissado e empossado, o funcionário entra em exercício e, destarte, se integra na hierarquia; em ato, sempre que o superior hierárquico, atentas necessidades definidas do serviço administrativo, emana ordens administrativas, para que sejam elas removidas.

Quem é obrigado a obedecer a ordem é sujeito passivo na relação jurídica, acessória, de que falámos; quem a formula e espera, lògicamente na execução, por que se lhe concretiza a obediência, chama-se: sujeito ativo. $O$ sujeito ativo da ordem administrativa, conquanto seja pessoa física e, como tal, seu agente ostensivo, a qualidade de quem a dá, é órgão da Ad. Pública, de quem, na realidade, procede a ordem, quando legal.

4 - A relação jurídica em tela não pode nascer, à vista do que há pouco expusemos, do mero desejo individual de mando de quem quer que, eventualmente, se identifique com o órgão. Como potência, descende ela da hierarquia; como ato, nada mais representa que uma emanação da potência, fundada na imposição de circunstância que o serviço administrativo apresenta. O ordenado fica obrigado, porquanto está vinculado ao dever de obediên- 
cia, em face do ordenador, precisamente porque anuiu a tôdas as cláusulas legais da relação de função pública. $O$ ordenador fica preso ao dever de emanar ordem, de conformidade com a lei. Tiram-se do até aqui dito estas conseqüências: I) na ordem, impõem-se sua conformidade e sua harmonia com a lei; II) não havendo conformidade, nem harmonia com a lei, a ordem não pode ser tributária de obediência. Daí mesmo poder-se concluir: a) que não é ordem administrativa qualquer determinação individual de pessoa física, que, por ser chefe, a faz, sabendo-a alheia ao interêsse do serviço administrativo; b) que não o é, por igual, aquela que fira a lei, quer por importar, com a execução, ato ilícito, quer por importar favor, praticado em circunstâncias prejudiciais ao interêsse do serviço administrativo.

5 - Qualquer que seja a forma de exprimir a vontade na ordem (forma oral, forma escrita, forma por sinal, ou por silêncio de interpretação pré-estabelecida), não é ela sequer digna do objetivo "administrativa", se não condiz com o serviço administrativo, ou se, embora condizendo, não se enquadra na lei, ou fere direitos.

6 - É pacífico, em doutrina, que as ordens emanadas de superior hierárquico devem ser obedecidas, em princípio. Mas, também o é que, ao emaná-las, deve o superior hierárquico recordar que assim procede como órgão e não como pessoa física, eventualmente identificada com êste. A hierarquia contrapõe órgão a órgão e nunca indivíduo a indivíduo. ${ }^{1}$

7 - 0 requisito da legalidade é que vincula o ordenador (sujeito ativo) ao ordenado (sujeito passivo) e ambos, em suma, à lei. Não o havendo, nenhuma vinculação existe.

(1) Galateria ("Teoria Giurídica degli ordini amministrativi", págs. 17, n. 2 e 32 , n. 2); RANellettr ("Istituzioni di Diritto Amministrativo", pág. 494); AмоRTH ("La nozione di gerarchia”, pág. 15). 


\section{3. ) Encarecimento da legalidade da ordem.}

8 - A ordem a ser obedecida pelo subordinado chama-se: Administrativa. Para que tal nome leve, carece ela de provir de órgão competente, bem como de pressupor que sua execução não importe ferir a lei. Quanulo, portanto, o contrário sucede, a ordem não deve ser obedecida. Mas, a extensão dêste princípio, ou a sua restrição, na prática, depende de exame das teorias sôbre o dever de obediência em contraposição ao direito de resistência. Ł o de que, a seguir, trataremos.

$4^{\circ}$ ) Teorias sôbre a extensão do dever de obediência.

9 - Duas orientações podem ser assinaladas na doutrina, a propósito da extensão do dever de obediência do funcionário público. A primeira delas nos vem pelo conhecimento da opinião da Corrente Hierárquica; a segunda pela Corrente Legalista.

10 - Segundo as idéias da Corrente Hierárquica, deve o funcionário obedecer cegamente as ordens do seu superior hierárquico. Não lhe cabe refletir sôbre a ilegalidade da ordem e qualquer reflexão que realize a respeito não o pode dispensar de cumpri-la. Do contrário - entendem os adeptos da corrente - subverter-se-ia o princípio hierárquico.

Como crítica à opinião exposta, cabe-nos desde logo notar: ela advoga o caráter absoluto para o dever de obediência, idéia cujas raízes se projetam em influência residual dos pensamentos alentadores das antigas monarquias absolutas. Daí podermos dizer, antecipadamente, que, hoje, seu valor não vai além do histórico ${ }^{2}$. A vul-

(2) A conexão entre as monarquias absolutas e a teoria sustentada pela Corrente Hierárquica foi posta em foco pela elegante pena de ORLANDo ("Principii di Diritto Amministrativo", ed. de 1910, pág. 112.) Todavia, é-lhe favorável, ainda que reduzidamente, MaNziNI ("Tratt. di Diritto Penale", I, pág. 253). Admiráveis críticas à Corrente são feitas por ZANOBINI ("Corso di D. Amm", 3.a ed. III, pág. 236) e Romano ("Principii di D. Am", 2.a ed., pág. 78). 
nerabilidade da teoria é flagrante. A sugestão de obediência cega importa em considerar os funcionários uns títeres. Porém, não cuida de que, como humanos, não fogem êles da responsabilidade, ou da co-responsabilidade. Finalmente, ignora, (porque no tempo de seu prestígio isto não foi suscitado) que a hierarquia não se passa entre pessoas físicas, mas entre órgãos ${ }^{2-A}$. A despeito do que vai dito, seria, de todo em todo, inútil esquecer a circunstância de que à Corrente Hierárquica pertenceram autores de indiscutível valor ${ }^{3}$.

11 - Examinemos, agora, as liçôes da Corrente Legalista, a qual, como bem indica o nome por que é conhecida, se caracteriza pela nota especial de sobrepor o mandamento legal à hierarquia e não assim esta àquêle, como sucede na Corrente hierárquica. Muito de indústria, falamos em lições, visto como os adeptos da Corrente Legalista se agrupam em três tendências, segundo veremos logo.

Principiemos pela tendência ampliadora. Sabemos que os seus sustentadores proclamaram estas idéias, a propósito do tema que aqui se fere: - nenhum subordinado é obrigado a obedecer quaisquer ordens ilegais emanadas de seus superiores hierárquicos. Aparentemente inatacável, assim que enunciada uma tal lição, logo nos merece simpatia, até o instante em que, por mais um pouco de reflexão, lhe divisamos o exagêro. Este transparece na amplidão de sua fórmula, em que fica nìtidamente incluído que quer se trate de ilegalidade manifesta, quer se trate, ainda, de ilegalidade duvidosa, a desobediência é legítima.

O ponto passível de crítica e de onde se colhe o exagêro em que a lição labora está precisamente em ela ser uma antítese absoluta da Corrente Hierárquica. Esta,

(2-A) Cf. nota 1 de rodapé, supra.

(3) Cf. Laband ("Le Droit Public de l'Empire Allemand", II, pág. 146); MAYER ("Droit Administratif Allemand”, IV, pág. 72); NÉZARD ("Les principes généraux du Droit Disciplinaire", págs. 154 e 146.) - Para proveitosa compreensão dos excessos de tal lição, é de se ler a crítica de Galateria (ob. cit., págs. 192 a 195). 
como vimos, sugere que o caráter absoluto da obediência é uma necessidade por amor da hierarquia, chegando, por isto, a esquecer que o funcionário é um ser pensante e que, ainda que o considerássemos um títere, não fugiria êle da responsabilidade, ou da co-responsabilidade pelo cumprimento de ordens ilegais. A lição da Corrente Legalista Ampliadora, sugerindo o caráter absoluto do direito de resistência, subverte a hierarquia. Em suma, realiza aquilo que, com exagêro, a Hierárquica visou a evitar. Se não, vejamos.

A Corrente Legalista Ampliadora esquece que, embora seja certo e lógico que todos os funcionários são seres pensantes, nem todos os seres pensantes, de que os funcionários são espécie, são dotados de meios para discernir o que ultrapassa da ilegalidade manifesta. Esquecendo e porque esquece, ela prevê, à falta de tal discernimento, balbúrdias entre o superior e o subordinado em torno do que é duvidosa e do que ostensiva ilegalidade ${ }^{4}$. Não seja, contudo, esta circunstância bastante para servir de motivo para que caiamos no defeito da lição intermédia da Corrente Legalista. Esta é, de um lado, restritiva, e, de outro, ampliativa. Restritiva, quando admite a desobediência do funcionário apenas quanto a ordens cuja execução importe ato, ou omissão criminosos. Ampliativa, quando acrescenta que também é legítima a desobediência, se o cumprimento da ordem importa na prática de ato imoral ${ }^{5}$ É que a teoria celebra a honestidade e a tutela, e, no entanto, quanto aos ilícitos, só leva em conta o criminal, olvidando que, no Direito Positivo, não é o crime o único impedimento da liciedade das ações humanas.

(4) São adeptos da Corrente Legalista Ampliativa: DuguiT ("Traité de Droit Constitutionnel", 2. ${ }^{2}$ ed., II, pág. 275, e III, pág. 285); VITTA ("Il potere disciplinare sugli impiegati pubblici", pág. 342) ; ORlando ("Principi" cit., pág. 111).

(5) São adeptos da Corrente Legalista Intermédia: HaURiou ("Précis de Droit Administratif", 11." ed. pág. 50, n. 2) : D'Alessio ("Istituzioni di Diritto Amministrativo Italiano", I, pág. 68). 
O caminho da razão, segundo cremos, está na $3 .^{a}$ lição da Corrente Legalista: só é legítima a resistência, quando a ordem emanada do superior hierárquico é manifestamente ilegal; quando ela é legal, ou duvidosamente ilegal apenas, merece obediência e deve ser cumprida ${ }^{6}$.

5) Auto-Avaliação passiva da ordem administrativa.

11-A - Excluíndo-se a lição da Corrente Hierárquica, porquanto acreditamos ter demonstrado que isto é medida que se impõe, resta, é claro, uma pressuposição: a admissibilidade de o funcionário, ao receber uma ordem emanada de seu superior hierárquico, poder sindicar da sua legalidade antes de a executar. Esta faculdade, que é pressuposto necessário sempre que se trate de adotar qualquer modalidade das lições da Corrente Legalista, é chamada em doutrina: auto-avaliação passiva da ordem ${ }^{7}$.

Sôbre a extensão atribuível a tal poder de sindicância há, em doutrina, movimentada discussão. Esta gira em tôrno de saber-se se a auto-avaliação passiva de uma ordem administrativa pode limitar-se a aspectos formais, ou ainda, pode abranger aspectos materiais ${ }^{8}$. E que, nesta altura dêste trabalhinho, iremos estudar.

12 - Uma lição é de parecer que o exame pode ser extendido da forma à substância da ordem, no que se tange com a sua legalidade ${ }^{9}$. Críticas há que, feitas a ela, concluem que de admiti-la se seguiria a subversão da hierarquia ${ }^{10}$ Data venia, não aceitamos tal censura. Não compreendemos que se admita a auto-avaliação passiva parcial, visto que, se concordássemos com ela, con-

(6) São adeptos da Corrente Legalista Restritiva: MEUccr ("Istituzioni di Diritto Amministrativo" $3 .^{\mathrm{a}}$ ed., pág. 237) ; JÈze ("Les principes généraux de Droit Administratif", III, págs. 521 e 522).

(7) Cf. Galateria (ob. cit., pág. 95).

(8) Cf. Galateria (ob. cit., págs. 95 e segs.).

(9) Cf. Galateria (ob. cit., pág. 95) - v. também Royo VilaNova (S.): "Derecho Administrativo", 1929, pág. 97.

(10) Crítica de Laband (ob. cit., págs. 148 e 149). 
correríamos para a fusão da Corrente Hierárquica e da Corrente Legalista, fragmentando-as. Ou bem - e isto é o que traduz nosso pensamento - admitimos que o funcionário sindique da legalidade de ordem administrativa, sem distinção especial, ou bem não o admitimos. Limitando a auto avaliação à forma, admitimo-la em parte, e esposamos, em suma, solução que não acode, em casos concretos, a uma realidade: a de que a ilegalidade pode ser formal, ou substancial numa ordem administrativa.

13 - Outros escritores, não se atendo à fragmentação acima acenada, nos vêm a oferecer outra solução, que é chamada teoria da repetição, ou demonstração. Consiste em, emanada uma ordem e sobrevinda a auto-avaliação, caber ao funcionário, no caso de concluir pela sua ilegalidade, repeti-la ao chefe, fazendo-lh'a ver, a fim de, insistindo o ordenador, cumpri-la ${ }^{11}$.

Seria imune de restrições tudo quanto a teoria da repetição aventa, se a representação sôbre a ilegalidade, seguida da desobediência, porventura, pudesse, em tôdas as hipóteses, equivaler a uma verdadeira ressalva. Isto, entretanto, sòmente é possivel, quando a execução não redunde na prática de ato ilícito. A representação, em caso de crime, não é ressalva; é, pelo contrário, uma confissão que, equivalendo a conivência, integra o ordenador o ordenado na co-autoria, anàlogamente ao que sucede no chamado: mandatum sceleris ${ }^{12}$.

14 - Melhor é, em hipóteses de ordens manifestamente ilegais, tanto do ponto de vista formal, quanto material, of erecer-se-lhes resistência passiva, deixando puramente de as cumprir. Foi tal, aliás, a solução a que abordou o art. 194, n. vII, da Lei Federal n. 1.511, de 28 de outubro de 1952.

(11) Ferraris ("Diritto Amministrativo", II, pág. 316).

(12) Cf., também, a extensa crítica de Galateria (ob. cit., págs. 199 e 201). 
15 - Não é aceitável a opinião de quantos, depois de dividir os órgãos em executivos e não-executivos, para os efeitos da discussão do assunto que agora nos ocupa, concluem que uns devem ter sindicato completo sôbre ordens administrativas e outros não o devem ter ${ }^{13}$. É que também ilógica se nos depara fragmentação com base numa classificação arbitrária. O poder de sindicabilidade é dado ao funcionário, porque é racional que nós o consideremos ser pensante e não assim porque seja pequeno funcionário, ou alto funcionário. Portanto, ou nos filiamos por inteiro à absurda sustentação de que a obediência deve ser absoluta, e não há que considerar sindicato algum, ou, filiando-nos ao que de melhor nos propõe a Corrente Legalista, temos que dar sindicato a todos os funcionários, e não assim a alguns apenas.

16 - A conclusão de se tirar de tudo quanto até aqui foi dito é a seguinte:

a) admitida a teoria de que o funcionário não é obrigado a obedecer ordens manifestamente ilegais, cossectário lógico é que se conceda ao que deve obedecer a possibilidade de sindicar da legalidade do que lhe é determinado pelo seu superior hierárquico;

b) realizada a auto-avaliação passiva da ordem administrativa, a resistência tem emersão legítima, se da sindicância resultar a conclusão incontestável de que a ordem é manifestamente ilegal.

6) O dever de obediência nos nossos estatutos.

16-A - O estatuto de 1952 para os funcionários federais (Lei Federal n. 1.711, de 28 de outubro de 1952) no seu artigo 194, n. VII, dispõe: É dever do funcionário: “Obediência às ordens superiores, exceto quando manifestamente ilegais".

(13) Cf. ORLando (ob. cit., págs. 113 e 114) ; Zanobini ("Corso" cit., III, pág. 237) Romano ("Corso di Diritto Amministrativo", pág. 119 e 120) 
Diante do texto, deve-se concluir que, em vista de sua redação, em caso de ordem manifestamente ilegal, é bastante não a cumprir. É a resistência passiva, que se funda no princípio de que a ninguém cabe fazer o que a lei não obriga ${ }^{14}$. Nem sempre, segundo veremos, a orientação estatutária foi tal entre nós. A orientação do Decreto-lei federal n. 1.713, de 28 de outubro de 1939 e dos estatutos de todos os aparelhos administrativos nacionais por êle modelados e dos quais existem ainda muitos em vigor eram a seguinte: ordem administrativa, quando ilegal de manifesto, deveria ser executada, embora representada a ilegalidade pelo executor. Esta solução deixou de ser defensável em face já do que dispuseram os arts. 19, n. III e 25 do Código Penal de 1940, que incluiu na conivência quem, por qualquer modo, prestasse colaboração a crime (v. n. 13 supra).

\section{III}

\section{O dever de sigilo do funcionário público}

\section{1) Interêsse no segrêdo.}

17 - Como todos o sabem, o segrêdo pode interessar tanto à moral, quanto ao direito. Daí a razão por que, para que sua inobservância não ficasse impune, a lei lhe destinou expressa reação sob as formas casuísticas de pena civil e criminal, e, ainda, nalguns exemplos, de penas disciplinares. Entretanto, a nenhuma lei pertence definir em que consiste o segrêdo. De sorte que a sua amplitude, para aquêle que o deve guardar não é extremada pela lei e, sim, pela doutrina.

Pôsto que a lei não deva definir, uma há que, conquanto ordinàriamente não o faça, tem de incluir, na sua essência, elementos de que, em harmonia e articulação, se depreendam idéias que nos proporcionem uma noção.

(14) Constituição Federal de 1946, art. 141, parágrafo 3. 
Trata-se da lei penal. Esta exigência não é universal para contradizer o sábio princípio de que a definição em lei se apresenta perigosa, como já vinha em Javoleno; ela se apresenta como necessária para que a fixação do fato ilícito penal e a pena mesma que se lhe destine não sejam frutos de analogia, sobretudo nos dias em que é dominante no Direito Penal Positivo a tipicidade, expressa no "nullum crimen sine lege", adversária da precaridade dos suplementos gerais de direito. No caso do dever de segrêdo, a lei tipificou - mas, não deixou senão menção a êle, pois, a complexidade ideológica do seu conteúdo não permite maiores minúcias. Proibiu ela a revelação de segrêdo. Mas, não disse em que consistia êste. Por esta razão cabe à doutrina determinar o que é segrêdo. Por outras palavras: o que é aquilo que é vedado revelar. Esta ida à doutrina vale tanto para o crime, quanto para o delito civil e para a transgressão disciplinar.

18 - Daqui por diante, vamos particularizar nossas observações ao funcionário público. Êste tem dever de guardar sigilo de ofício, isto é, de não concorrer para que o que saiba em razão do cargo, função, ou emprêgo, seja revelado, ou não facilitar-lhe a revelação. Ora, são incontáveis os fatos de que o funcionário tem ciência na repartição pública em que trabalha. Como poderá, pois, distinguir quais os que, revelando, comete crime, dos que, revelando, não comete? Bastará seu critério subjetivo? E se êste falhar, poderá defender-se, alegando que supunha que não se tratasse de segrêdo aquilo que revelou? O critério de distinção não pode, nem deve ser obra de elaboração mental daquele a quem incumbe preservar o segrêdo de ofício.

19 - Segrêdo vem de secretum. Esta palavra exprime, em sentido etimológico, a idéia do que deve ser guardado. E o ser guardado, aqui, não quer dizer senão o que deva permanecer na ciência de alguns que o não 
devem revelar. De secretum é antônimo o publicum, que exprime, por sua vez, a idéia do que já é notório. Logo, por exclusão, deve-se entender que segrêdo é tudo quanto ainda não é público nem notório. Noutras palavras: segrêdo é aquilo que ainda não é público, nem notório. Esta condição, que satisfaz plenamente ao conceito solicitado pela moral, é meio caminho andado no direito. Neste, segrêdo é tudo quanto, não se achando ainda na notoriedade, se revelado, causa dano, ou pode causá-lo. Assim, para a lei, revela segrêdo todo aquêle que divulga o que não é do conhecimento público e, fazendo-o, pode vir a causar dano, ou chega mesmo, com a revelação, a efetivamente causá-lo.

2) O segrêdo e o funcionário público.

20 - $\mathrm{O}$ dever de segrêdo relativamente a certas profissões e estados, implícitos em subordinação especial explicativa de disciplina, tais como, v. g. advogados, médicos, sacerdotes, militares e funcionários públicos, é tutelado em três aspectos: civil, penal e disciplinar. $O$ funcionário acha-se no rol dos exemplificados. Conseqüentemente, o dever de segrêdo the incumbe nos três aspectos apontados, razão por que é tutelado na lei civil, na lei penal e na lei administrativa. Se não, vejamos.

Entre nós, a lei civil tutela o dever de segrêdo, quando o Cód. Civil, no art. 114 declara que, em juízo, há opção entre revelá-lo, ou não o revelar. A lei penal, tutelando-o, deciara no art. 325 que é crime o funcionário público revelar fato de que tem ciência em razão do cargo, desde que tal fato deva permanecer em segrêdo. Na lei administrativa, o segrêdo é também tutelado. O legislador, porém, aí não pode considerar crime a sua revelação. Limita-se a estimar que seja preservado em interêsse do bom andamento do serviço administrativo e, por isto, o tutela, declarando que revelá-lo é transgressão desciplinar (Lei Federal n. 1.711 , de 1952, art. 194, n. II, combinado com o art. 207, n. VII). 
Em suma: revelar segrêdo é crime, é transgressão disciplinar e pode dar aso a reparação econômica do dano. Por outro lado, quer como ilícito penal, ou civil, quer como ilícito administrativo, segrêdo revelado é divulgação do que, ainda não sendo público e notório, com a revelação pode causar dano, ou vem efetivamente a causá-lo. Mas, tal dever não tem fronteiras? Isto é o de que, por último iremos tratar aqui neste trabalhinho.

3) Exceções ao dever de segrêdo do funcionário público.

21 - Dúvida alguma há que a revelação do segrêdo viola um bem (no sentido filosófico do "quoad beatus faciunt"), porque pode causar dano à honra, à fama, à liberdade, ou até atingir cousas, isto é, bens em sentido de partes positivas de um patrimônio. É de se notar, porém, que, nem por isto a lei deixa de o liberar, quando considerações superiores aconselham temperança.

No Direito Brasileiro, o dever de obediência comporta exceções. Estas se limitam, contudo, a casos em que há jurisdição em linha de conta, entendidos por tais o juízo de atuação permanente e os casos de jurisdição incidente, de que é exemplo eloqüente o juízo arbitral.

22 - Dispõe o Código Civil, no seu artigo 144: "Ninguém pode ser obrigado a depor de fatos, a cujo respeito, por estado, ou profissão, deva guardar segrêdo". Por êste preceito, verifica-se que, referindo-se à prova no procedimento judiciário civil, é de se concluir de sua leitura o seguinte: o que extra-judicialmente é dever absoluto segredar, não o é em juízo. Defere o dispositivo legal à testemunha decidir livremente se revela, ou não revela o segrêdo em juízo. Se se decidir a revelá-lo, presta homenagem à nobre função do juiz e, especialmente, aos interêsses da Justiça; se se decidir a não o revelar, como que se recompõe integralmente com o seu fôro íntimo e sòmente com êste. Todavia, em ambos os casos está com a lei e dentro desta, razão por que há, em favor da teste- 
munha que deva guardar segrêdo, espécie de poder discricionário, se nos é permitido perpetrar uma metáfora ${ }^{15}$. Mas, a verdade é que a disposição não pôde vigir por inteiro, depois do surgimento do Código de Processo Civil e Comercial Nacional. Antes dêste, era dado ao juiz chamar qualquer funcionário para que êste desse o seu testemunho, observado exclusivamente o art. 144, do Código Civil. Mas, o Decreto-lei n. 1.808 , de 18 de setembro de 1939 , em seu artigo 236, sobreveio a exigir a precedência de uma requisição do funcionário, feita pelo juiz ao respectivo chefe daquele, o que importa uma ligeira alteração, nos segs. têrmos: Não pode o funcionário servir de testemunha, ainda que queira dar o seu testemunho, sem ser requisitado na forma do c. P. c. c. N. art. 236. No mais, fôrça é confessar que não houve alteração. Assim, ainda que regularmente requisitado, pode o funcionário recusar-se a dizer em juizo dos fatos que importam segrêdo, ou revelàlos ali, porquanto é o que ainda se lê do art. $241, n$. II do Código de Processo Civil.

Em síntese: antes do Código de Processo Civil Nacional, só ao funcionário cabia decidir se, indo a juízo, a fim de depor como testemunha, revelaria, ou não revelaria segrêdo que soubesse em razão do cargo; depois do refe-

(15) As idéias de que a liberdade, como direito de fazer ou deixar de fazer dentro da lei, se aproxima da atividade discricionária são antigas nos estudos de direito e se baseiam no caráter "polissenso", como lhe chamou Giannini ("Il potere discrezionale della Pubblica Amministrazione, pág. 21) da palavra "discrição" e da palavra "discricionariedade". Srotto Pintor no "Foro Italiano" de 1911, vol. I, pág. 1029 demonstrou que embora o poder (ainda que limitável sempre) pudesse, como freqüentemente é, ser restringido, a discricionariedade é, por definição, indeterminada. Esta concepção põe têrmo, na essência, à de LAUN na qual aparece o poder discricionário ùnicamente a compreender a idéia de duas e não mais soluções legais disjuntivas ("disjunktive normen") opostas a soluções legais categóricas e, portanto, vinculantes ("kategorische normen"). Sôbre o assunto em citação, a que nos reportamos, cf. GianNiNi (ob. cit., págs. 9 a 27 de notas de rodapé ns. 1 a 20). 
rido diploma legal, para que tenha o poder de opção conferido pelo artigo 144 do Código Civil e use dêle, como lhe fizer bem à consciência, é necessário que seja requisitado à repartição em que trabalha, visto que, faltando a requisição, nem a juízo sequer pode ir a fim de, instado a depor, escolher entre guardar ou revelar segrêdo.

23 - No processo penal, as idéias não coincidem totalmente com as que tivemos o ensêjo de examinar quanto ao processo civil. Primeiramente, nele, a lei não impõe a precedência de uma requisição, como a prevista no c. $P$. c. c. N. art. 236. Contudo, o funcionário está proibido de depor, como testemunha, se não é desobrigado, por aquêle a quem interessa o segrêdo e, se, porventura, se lhe confere a desobriga, retorna à decisão de seu fôro íntimo anuir ao dar seu testemunho, ou recusar-se a fazê-lo, se o de que se trata é de fato que deva permanecer em segrêdo. $\leftleftarrows$ o que se lê no Código de Processo Penal, baixado pelo Decreto-lei n. 3.689, de 3 de outubro de 1941, quando êle, de um lado diz que a testemunha não se pode eximir de depor (art. 206) para declarar, a seguir: "São proibidas de depor as pessoas que, em razão de função, ministério, oficio ou cargo, devam guardar segrêdo, salvo se, desobrigadas pela parte interessada, quiserem dar o seu testemunho".

Em resumo: para depor em juízo criminal, a mera deliberação de o funcionário fazê-lo é insuficiente. E preciso que êle seja desobrigado pela parte, ou partes a quem interessa o sigilo, para que, então, possa dar o seu testemunho, se o quiser.

24 - Muito interessante é indagar da natureza jurídica daquilo a que o artigo 207 do Código de Processo Penal de 1941 nos leva a chamar pelo nome de Desobriga. De que natureza participa? Se o interessado na guarda do segrêdo é o particular que, eventualmente, se viu na contingência de confiá-lo à Ad. Pública, (como, v. g., sucede 
em alguns serviços administrativos médicos), tal Desobriga não pode traduzir senão uma renúncia. Aquêle a quem aproveitaria o segrêdo, renuncia o direito ao segrêdo, despojando-se do bem, que, em sentido amplo, a sua revelação pode pôr a perder. A dificuldade sobe de ponto, quando se trata de determinar a natureza jurídica da Desobriga, quanto a segrêdo de que o único interessado é o Estado. Em tal hipótese, como é possível caracterizá-lo? Não há dúvida que sôbre haver nela algo do que sugere a renúncia é fato manifesto. Mas, convém, que nos alonguemos na análise da espécie, para que nos aproximemos de uma solução razoável.

Depor sem desobriga é atividade proibida, quando se é vinculado ao segrêdo. Tal circunstância faz crer que a Desobriga é uma autorização administrativa, visto que esta é ato administrativo pelo qual se remove obstáculo que, por lei, impedia a atividade autorizada, por tal modo que, se exercida antes dela, seria proibida. A solução é, porém, inaceitável. Em primeiro lugar, porque a autorização administrativa tem por objeto o comum administrado, isto é, o particular; em segundo lugar, porque, embora discricionária como parece também ser a Deso. briga, esta não é revogável e seria inútil, para os efeitos de prova que o testemunho apresente, revogá-la, quando já produziu os seus efeitos e êstes, por definitivos, não podem ser golpeados pela revogação. Logo, se não é autorização administrativa, quê pode ser? Afigura-se-nos que seja um tipo especial de dispensa administrativa, que é, como se sabe, relaxação casuística da lei, para desonerar quem, por ela, pode ser pôsto à margem de um dever jurídico. ${ }^{16}$ Cabe-nos, entretanto, dar esta solução que reputamos apenas um aceno, para considerações mais largas do que as que fizemos.

(16) Cf. BopdA ("La Dispensa Amministrativa", passim). 
25 - Aqui finalizamos. Ferimos os pontos fundamentais das questões propostas e, porque o fizemos a considerar que o tempo urgia e o espaço rareava, não pudemos dar a êste trabalhinho mais do que um sentido de esquema. Eis a razão por que nos despedimos a dizer: os doutos dirão melhor ${ }^{17}$.

(17) Cf. Ords. Manuelinas, liv. 1, título 55, parágrafo 2; Ords. Filipinas, liv. 1, título 76, parágrafo 2; ALBERICI ("Eccessioni al dovere di testimonianza", Turim, 1910) ; Di GIORgio ("La rivelazione del segreto amministrativo" na Rivista di Diritto Pubblico, I, 1. ${ }^{\text {a }}$ parte, págs. 226 a 242) Cf., também, nosso manual intitulado "Crimes contra a Ad. Pública", 1955, págs. 138 a 147, ns. 251 a 261.) Lúcido estudo produziu-o o professor Basileu Garcia, cf. "Revista da Faculdade de Direito", vol. 44 (1949), págs. 51 a 67 sob o título: "Violação de segrêdo". Merece leitura, ainda, WaLdemar Cesar dA Silveira ("Dos crimes praticados por funcionário público contra a Ad. Pública em geral" nos Anais do $10^{\circ}$ Congresso Nacional do Ministério Público, vol. V, pág. 189.) No passado, versou o assunto José Mendes: “Testemunha que diz a verdade em juízo cumpre o seu dever e não comete crime" (ed. Duprat, S. Paulo, 1906). 